\title{
Strategies Of SuPPorting Progressed Learners For Quality TEACHING AND LEARNing In VHEMBE DisTriCt, LIMPOPO, SOUTH AFRICA
}

\author{
Fhulufhelo Patrick Muedi ${ }^{1)}$, Azwidohwi Philip Kutame ${ }^{2)}$, Thelma Ngidi ${ }^{3)}$, Chinaza Uleanya ${ }^{4)^{*}}$ \\ 1) University of Zululand, South Africa \\ E-mail: muedifp@unizulu.ac.za \\ 2) University of Zululand, South Africa \\ E-mail: kutameap@unizulu.ac.za \\ 3) University of Zululand, South Africa \\ E-mail:ngiditz@unizulu.ac.za \\ 4) University of South Africa, South Africa \\ E-mail: chinazamoses90@gmail.com
}

*)Corresponding Author

\begin{abstract}
Progressed learners differ from their counterparts. The difference is reflected in their assimilation, retention and abilities to reproduce what they are taught. Meanwhile, progressing learners due to policy is insufficient, certain support strategies are to be in place. Hence, the study investigated the strategies of supporting "qualified to be progressed" (QP) learners for quality learning and teaching. Mixed methods was employed for data collection. Random and purposive sampling techniques were used to select teachers and School Management Team (SMT) members respectively who formed the study sample. The study was conducted in 10 purposively selected secondary schools in the Vhembe education, Limpopo, South Africa. Questionnaires were used to collect data from 165 selected teachers who were the respondents for the quantitative part of the study. Meanwhile interviews were conducted for the 10 SMTs who formed the participants for the qualitative part of the study. Percentage was used to analyse the quantitative data, while the qualitative data were used for triangulation. The finding of the study showed amongst others that there are no specific support strategies put in place to assist progressed learners to catch up with their counterparts. The study recommends that schools and relevant education stakeholders put in place support strategies to assist progressed learners.
\end{abstract}

Keywords: Qualified to be Progressed (QP) learners; strategies; Vhembe Education District; Limpopo

\section{INTRODUCTION}

High dropout rate seems to be experienced in South Africa at different levels. According to Moodley and Singh (2015), many undergraduates drop-out from their first year in the university. This suggests that there are some possible challenges that might have been overlooked or were not duly addressed from their secondary education. Review of the work of Mansfield and Horwitz (2020) concurs that the challenge of many university dropouts are from secondary schools. According to Mansfield and Horwitz (2020), the dropout rate in South African secondary schools is alarming. Pretorius (2019) holds the view that South Africa has about one of the highest dropout rate in the global world. Meanwhile, in support of the earlier works of Uleanya and Gamede (2017), Weybright et al. (2017), Pretorius (2019) as well as Manfield and Horwitz (2020), Writer (2020) following the data presented by the Department of Basic
Education states that the dropout rate in South African schools is between $37 \%$ and $42 \%$. This indicates high dropout rates being experienced in South African schools. In an attempt to address the issue of high dropout rate in secondary schools, the Department of Basic Education (DBE) came up with a policy commonly described as "progression policy (DBE, 2017)." This policy is expected to guide school managements in progressing learners from one class to another. Following a report from the Department of Basic Education (2017), the policy is guided by a rationale which is to minimise the high dropout rate and maximise school retention. However, not all learners who fail are made to progress. There are certain criteria put in place (DBE, 2017). Amongst these criteria include: i. learners must have failed a particular grade two times. ii. must have attended school regularly. iii. they ought to have complied with the school based assessments in all subjects. iv. for learners who fall in the category of those to be progressed to be allowed to go to 
Grade 12 where matric examination is to be written, they are to be scrutinized to be sure that they must have passed at least four out of the seven subjects offered. Out of the four subjects to have been passed Life Orientation (LO), as well as Language of Learning and Teaching (LoLT) are compulsory. In congruence to the rationale behind the progression policy by the Department of Basic Education (DBE), Leepo (2015) supports the view for the need and the design of the development of Academic Performance Improvement Plans (APIPs).

According to Leepo (2015), APIPs are developed to identify learners who experience serious challenges, and such learners could be assisted through the development of intervention strategies. However, the questions remain: do intervention strategies exist in secondary school? Where they exist, how effective are they? Thus, the reason for this study which seeks to investigate the strategies adopted and/or put in place in secondary schools to support progressed learners. This investigation is done using a selected education district in the Limpopo Province of South Africa. In order to achieve the aim of this study, attempt is made to proffer answers to the identified research question guiding the study. The research question is: are there intervention strategies and programmes to assist progressed learners to catch up with promoted ones?

\section{METHODS}

Mixed methods approach was employed for this study. The adopted method allowed for the triangulation of collected data. According to Kumar (2019), adoption of mixed methods approach in a study can be used for triangulating both quantitative and qualitative collected data. The sample of the study comprised teachers and School Management Team (SMT) members from 10 selected secondary schools in Vhembe education district in Limpopo Province, South Africa. Purposive sampling was used in selecting the schools, while random and convenient sampling techniques were used to select the teachers and SMT members respectively. The randomly selected teachers who comprised the respondents of this study were 135, while the 10 SMT members were conveniently selected. Random sampling was used for the teachers to give as many as qualified the opportunity to partake in the study.

This is in accordance with the work of Kumar (2019) and Creswell (2014) who state that random sampling technique can be adopted in a study to avoid bias and give all who qualify to partake in the study. Convenient sampling was used in selecting the SMT members. This was due to their time schedule, availability and interest to partake in the study. Kumar (2019) and Creswell (2014) agree that convenient sampling can be adopted in selecting respondents or participants of a study based on certain criteria such as their interest in the study, among others. In brief, while the selected teachers took part in the quantitative part of this study, the SMT members were engaged in the qualitative part.
Questionnaire was used for data collection for the quantitative study. The questionnaire comprised two sections. The first section of the questionnaire was targeted at collecting demographic data of the respondents. The second section of the questionnaire focused on collecting data on support strategies available in the schools in assisting progressed learners. Conversely, interview schedule guide was used to collect information for the qualitative study which was used for triangulating responses from the quantitative data. The quantitative data was analysed using percentage, while the qualitative data were used for triangulation following identified themes generated from the analysed data.

\section{RESULT AND DISCUSSIONS}

The findings of the study are presented following the research question guiding the study. The demographic data of the respondents and participants of the study are first presented followed by the analysis from the collected data.

TABLE I

RESPONDENTS' PERSONAL INFORMATION

\begin{tabular}{lll}
\hline Gender & Frequency & Percent $(\%)$ \\
\hline Male & 70 & 51.9 \\
Female & 65 & 48.1 \\
\hline Age Range & Frequency & Percent $(\%)$ \\
\hline $25-35$ & 14 & 10.4 \\
50-65 & 31 & 31.0 \\
\hline Qualification & Frequency & Percent $(\%)$ \\
\hline M+2 & 1 & 0.7 \\
M+3 & 26 & 19.3 \\
M+4 & 84 & 62.2 \\
M+5 & 24 & 17.8 \\
\hline Teaching Experience & Frequency & Percent $(\%)$ \\
\hline 0-5 years & 22 & 16.3 \\
6-20 years & 80 & 59.3 \\
21-36 years & 33 & 24.4 \\
\hline Position Held & Frequency & Percent $(\%)$ \\
\hline School & & \\
Principal & 8 & 5.9 \\
Deputy Principal & 5 & 3.7 \\
HOD & 26 & 19.3 \\
PL 1 Educator & 96 & 71.1 \\
\hline
\end{tabular}

Table 1 indicates that $51.9 \%$ of the respondents were males, while $48.1 \%$ were females. Table 1 further shows that $66.6 \%$ were teachers within the age range of $36-49,10.4 \%$ were between 25 and 35 years, while those between the age range of 50 and 65 constituted about $31 \%$ of the respondents. Also, during the qualitative data collection stage, 10 SMTs were interviewed. Of these, only one principal was a female aged 48. The rest were males who range between the age of 48-55 years. Table 1 also indicates that most of the teachers who formed part of the respondents of this study have relevant subject content knowledge. Meanwhile, only one respondent has Grade 12 and a teacher training qualification of two-years. Regarding the experiences of respondents, $59.3 \%$ have been teaching for approximately between 6 and 20 years. This suggests that many of the teachers are 
experienced to manage the teaching and assessment in a class of learners with different cognitive levels. Respondents with $0-5$ years of were about $16.3 \%$. Meanwhile, teachers in this category are envisaged to be in need of support from the SMTs following that they seem to be novice as they have little experience. The respondents with the long teaching experience were between 21 and 36 years, and formed $24.4 \%$. This category of teachers is envisaged following their years of experience to be helpful in providing assistance to those who are less experienced in the management of teaching and assessing for quality activities in relation to teaching and learning.

Furthermore, Table 1 indicates that $71.1 \%$ of the respondents are post level one teachers. The HODs form $19.3 \%$ of the SMT members which offer subjects in Grade 12. However, $3.7 \%$ and $5.9 \%$ of the respondents respectively are principals and deputy principals. Meanwhile, they also teach Grade 12 learners. This implies that $9.6 \%$ of the respondents are SMT members with the administrative responsibility of making sure that the teaching and assessment of the QP learners is properly managed. In addition, these SMTs also monitor and support teachers in managing the teaching and assessment complexities of the QP learners for quality learning and teaching. Meanwhile, considering the number of HODs at the selected schools, it may be inferred that supervision of teachers may not be as effective as desired. This suggests that teachers do not receive enough support on how they should manage the teaching and assessment in a class of learners with different cognitive levels.

The findings from the analysed quantitative data are presented under various themes. Meanwhile the findings from the qualitative data are used to triangulate the quantitative findings.

Intervention strategies and programmes to assist progressed learners to catch up with promoted ones

TABLE II

SCHOOLS' DEVELOPMENT OF INTERVENTION STRATEGIES FOR PROGRESSED LEARNERS

\begin{tabular}{lll}
\hline Scale & Frequency & Percentage \\
\hline Never & 7 & 5.2 \\
Seldom & 7 & 5.2 \\
Sometimes & 22 & 16.2 \\
Often & 51 & 37.8 \\
Always & 48 & 35.6 \\
\hline Total & $\mathbf{1 3 5}$ & $\mathbf{1 0 0}$ \\
\hline
\end{tabular}

The information in Table 2 indicates that $35.6 \%$ of the respondents always develop the intervention strategies and programmes to assist progressed learners catch up with the promoted ones, while $5.2 \%$ never do that. The $35.6 \%$ is too low, and this implies that the majority of the QP learners here are not assisted to catch up with the progressed ones. This was confirmed by the principals who said that even though they have intervention strategies they develop at school level; they do not specifically address the catch-up issues concerning the QP learners. They emphasised that the strategies they develop cater for both the QP and promoted learners. Principal A stated that,

"Our school policy dictates that teachers should develop intervention strategies for their different subjects in the context of all learners. Developed strategies are discussed at different subject committee meetings to check if they are relevant and implementable. After all, these strategies are for all learners, not specifically for progressed ones only".

The response from principal A was echoed by principal G, who remarked that,

"We are on our own as a school. We do not have any assistance from the Department of Education when it comes to the development of intervention strategies. To improve the learners' performance in different subjects, all teachers participate in crafting the intervention strategies. Our teachers know how their learners perform, their strengths and weaknesses in different subjects. Thus, we are well positioned to develop intervention strategies for all these learners".

Given that schools are not assisted by the government; one might say that the progression policy is doomed to fail as such schools lack the much needed assistance from the DBE. Yes, teachers can and would certainly develop intervention strategies in this context, but of what use will these be if they are not in turn supported by the DBE through the provision of learning media to help them use those strategies effectively? In other words, the teachers' efforts here are a waste of time in as much as helping the QP learners is concerned. That is, the teachers' teaching and learning strategies would not matter in situations where the schools are under resourced.

Principal J noted that,

"In a class of QP and promoted learners, our teachers are able to select content and develop strategies that suit both sets of learners. They strategize using the previous grade's subject content wherein the QP learners are taught separately in order to narrow the content gap".

These comments comply with Opfer (2016) position that teachers should be allowed time to develop teaching strategies on their own as they know their learners' cognitive levels and the subject content suitable for them. This is also supportive of the work of Hattie (2009) who asserts that teaching strategies are generally multidimensional and they should be developed to cater for learners of different learning abilities. This suggests that strategies should be developed taking into account the subject content and the learners' abilities.

Only a few schools are able to develop intervention strategies that are specifically QP learner oriented, as evidenced by the $5.2 \%$ of the respondents who indicated that they never develop such intervention strategies. This is also an indication that if teachers do not develop intervention strategies that are specifically directed at improving the performance of the QP learners, it would be difficult for them to catch up with the promoted learners. Thus, unless teachers are encouraged to develop these strategies, the QP learners would continue to underperform. 


\section{Profiling QP learners for support}

Table 3 shows the profiling of learners after analysing school term results. This helped identify the challenging topics for support purposes.

TABLE III

THE EXTENT LEARNERS ARE PROFILED AND GIVEN SUPPORT AFTER EACH TERM'S RESULTS

\begin{tabular}{lll}
\hline Scale & Frequency & Percentage \\
\hline Never & 4 & 3.0 \\
Seldom & 8 & 5.9 \\
Sometimes & 37 & 27.4 \\
Often & 35 & 25.9 \\
Always & 51 & 37.8 \\
\hline Total & $\mathbf{1 3 5}$ & $\mathbf{1 0 0}$ \\
\hline
\end{tabular}

The figures in Table 3 show that $37.8 \%$ of the respondents always profile learners after analysing their results to identify challenging topics in order to provide them with support. About $27.4 \%$ sometimes do so, while 3\% never do anything about that. This indicates that the majority of learners are not profiled. Thus, teachers may not be able to identify areas where the QP learners still experience challenges in different subjects. They might continue to underperform as a result. Even though some of the principals confirmed during interviews that they profile the QP learners to identify challenging topics, there is a need for all schools to do so if the performance is to improve. These are some of the remarks by the principals, and principal A had this to say,

"Yes, we profile them according to item analysis and how they respond to different themes. We do profiling in order to check which topics give them challenges as the QP learners. This makes us choose appropriate approaches for the effective to teaching".

Principal $F$ added that,

"We encourage teachers to record marks when they give assessment tasks. Like what our Business Studies teacher does. He highlights in red all learners who fail tests four times to show that they are at risk. The moment one takes the mark sheet, one easily identifies the learners who are not doing well. We profile them according to their performance".

Principal I said that they profile learners according to how they performed in Grades 10 and 11 where they look at the subjects and sections they passed, and those they failed.

These principals' remarks auger well with Park, Ji and Lim's (2015) assertion that learner profiling helps the teacher to identify themes that learners experience challenges in or that need immediate attention. Park, Ji and Lim (2015) believes that when challenges in a subject are identified in this way, the teacher then selects suitable approaches to support the QP learners so that they improve their academic performance. Park et al. (2015) hold the view that learner profiling is the best strategy in identifying the learner's challenges in order to provide him/her with the relevant support. Tomlison (2001) is also in agreement that profiling learners assists the teacher in identifying learners at risk at the earliest convenient time. This means that if learners are profiled early, teachers would quickly provide support to those struggling with their studies.

\section{Lesson Planning for QP Learners' Activities}

Table 4 below shows the frequency with which teachers plan lessons for their QP learners.

TABLE IV

THE FREQUENCY WITH WHICH TEACHERS PLAN LESSONS FOR QP LEARNERS

\begin{tabular}{lll}
\hline Scale & Frequency & Percentage \\
\hline Never & 20 & 14.8 \\
Seldom & 8 & 5.9 \\
Sometimes & 41 & 30.4 \\
Often & 41 & 30.4 \\
Always & 25 & 18.5 \\
\hline Total & $\mathbf{1 3 5}$ & $\mathbf{1 0 0}$ \\
\hline
\end{tabular}

In Table 4, $18.5 \%$ of the respondents indicated that they always plan for the lessons to teach the QP learners, and $4.8 \%$ do not. This shows that the majority of teachers do not plan for the activities that would help them teach the QP learners. Nine principals also confirmed this when they stated that they do not plan for the activities when teaching the QP learners. To them, lessons are planned for all learners, not a specific category. This is how they responded, starting with principal A,

"It is not possible to prepare separate activities for the QP and promoted learners as they are in one class. We cannot separate them; we collectively handle them. In terms of lesson plans, the preparation is the same, but it terms of making them understand, the extension of the lesson plan is such that the QP learners are given simple tasks as they are slow learners".

Principals B emphatically said no, they do not plan for different activities but,

"We plan to teach the QP and promoted learners the same concepts. We only separate them in the afternoons where we teach them according to their weaknesses in different themes".

Principals C said that they do not plan lesson activities for the QP learners only. There are no lessons prepared for the QP and promoted learners separately.

Only one principal indicated that in his school, they plan for lesson activities that are specifically for the QP learners. He pointed out that,

"Yes, teachers plan and prepare content specifically for the Q.P learners, including the promoted ones who struggle with their studies. There are learners who were promoted, but do not perform well in class. They are grouped with the QP learners so that they are taught the same subject matter".

Here, the informants' responses are to the effect that they do not develop separate plans for concepts that specifically cater for the QP learners. This suggests that the DBE expects teachers to plan and prepare learning activities that ensures that the QP learners improve their performance. However, these teachers are not workshopped on strategies that enable them to handle mixed classes of learners with different learning abilities. Thus, if the QP learners are to do well in their studies, teachers should be trained on how to teach such 
learners effectively. It should be revealed that generally, the interviewees' observations here are not consistent with Tomlinson (2001) position that in a class where some learners experience challenges in certain themes, teachers should include activities that cater for that specific group of learners. Tomlinson (2001) believes that in almost every class, there are learners who require special consideration. If schools are to improve the QP learners' performance, they should include activities that cater for their specific needs.

\section{Extra lessons for QP Learners}

Table 5 contains information on the provision of extra lessons to the QP learners.

TABLE V

EXTENT TO WHICH EXTRA LESSONS ARE PROVIDED FOR THE QP LEARNERS

\begin{tabular}{lll}
\hline Scale & Frequency & Percentage \\
\hline Never & 14 & 10.4 \\
Seldom & 6 & 4.4 \\
Sometimes & 35 & 25.9 \\
Often & 43 & 31.9 \\
Always & 37 & 27.4 \\
\hline Total & $\mathbf{1 3 5}$ & $\mathbf{1 0 0}$ \\
\hline
\end{tabular}

The results in Table 5 show that $27.4 \%$ of the respondents always provide extra lessons to the QP learners, while $10.4 \%$ said that they never provide such lessons. These low percentages are an indication that even though the majority of the schools know that their QP learners do not perform as expected, they have failed to make any provisions for extra lessons to remediate this problem. The interviewees also admitted that extra classes are helpful in supporting learners who were progressed. However, they argued that there is no timetable designed for the QP learners' extra classes. They pointed out that this depends on individual teachers to make arrangements with their QP learners for extra lessons. Principal A's position here was that,

"It is not easy at our school. Teachers refuse to teach in the afternoon. They complain that given that at the Department of Education's Offices, employees there are paid overtime, while the same privilege is not extended to them if they work overtime. We teach all learners during school hours. It is quite difficult to convince teachers otherwise".

Principal C lamented that giving the QP learners special attention by conducting extra lessons is where they have challenges. He said that they only encourage all learners to do extra classes at identified centres that are funded by the Department of Education.

Principal G had this to say,

"We teach both the promoted and progressed learners the same themes in one class during school hours. There is no timetable for the QP learners' extra lessons. But, some teachers teach those who struggle in the mornings before the school starts, and in the afternoons after the prescribed working hours. Others teach progressed learners who struggle to cope with the content in the new grade after school hours only. Teachers usually repeat the content taught in class earlier".
Principal $\mathrm{H}$ bemoaned the system of teaching a mixed class of fast and slow learners thus,

"Honestly speaking, it is tough to teach a mixed class of QP and promoted learners during normal school hours. At our school, we emphasise on producing good results. As a result, teachers sometimes teach after school hours, even on Saturdays. They arrange with the QP learners to teach selected topics that were poorly done. In this way, teachers give learners individual attention. In turn, such learners are motivated to ask questions on issues they experience difficulties on".

The results in Table 5 and the principals' remarks contrast the findings of the work of Tomlinson (2001) who opines that today's classroom teacher is faced with the challenges of addressing a wide variety of learners' learning abilities. Tomlinson (2001) contends that to effectively manage a wide variety of needs, a teacher needs to identity learners who require additional support and provide extra lessons. If schools, therefore, want the QP learners' performance to improve, they should give them extra lessons.

This shows the teachers' willingness to provide extra lessons to the QP learners. However, the concerns raised by the respondents include, among others, the teachers' lack of skills or strategies to handle mixed classes of learners with different learning abilities, and the lack of incentives for teachers who give extra lessons after normal working hours. The department should provide incentives for teachers who are willing to teach after hours if the QP learners' academic performance is to improve.

\section{Control of QP Learners' Attendance}

Table 6 outlines the QP learners' school attendance monitoring frequency.

TABLE 6

THE EXTENT TO WHICH TEACHERS MONITOR QP LEARNERS' REGULAR SCHOOL ATTENDANCE

\begin{tabular}{lll}
\hline Scale & Frequency & Percentage \\
\hline Never & 9 & 3.7 \\
Seldom & 15 & 11.1 \\
Sometimes & 22 & 16.3 \\
Often & 39 & 28.9 \\
Always & 50 & 37.0 \\
\hline Total & $\mathbf{1 3 5}$ & $\mathbf{1 0 0}$ \\
\hline
\end{tabular}

The data in Table 6 reflect that $37 \%$ of the respondents always monitor their QP learners' regular school attendance, whereas $6.7 \%$ never do so. As such, less than half of the respondents monitor their learners' school attendance. This suggests that the majority of learners may always be absent from school or miss certain subjects without teachers noticing that. Nearly all the principals interviewed agreed that monitoring learner attendance is a policy that must be implemented without fail. However, principals noted that teachers do not monitor the QP learners' regular school attendance. On this issue, principal A expressed his thoughts thus,

"We monitor the learners' attendance through marking the daily attendance registers. The attendance registers are 
marked every morning during the first period, and in the afternoon during the last period. There is no separate attendance register for the QP learners".

Meanwhile, principal $\mathrm{C}$ confirmed that they use class attendance registers to monitor every learner's attendance trend. He acknowledged that there is no separate register for QP learners. Principal D pointed out that their learners, whether QPs or promoted ones, are monitored through the class attendance register whether they regularly attend school or not. Principal F added that they usually mark the learners' attendance registers every day when the school begins. He said that they pay special attention to the QP learners as they mark the registers because these sometimes absent themselves from school.

The above agrees with the work of Pitre (2010) who indicated that the attendance rate is important because learners are more likely to succeed in their academics when they consistently attend school. The study also revealed that some teachers do not effectively control their learners' attendance. This might negatively affect the QP learners' performance as they get less exposed to the curricula due to their misdemeanours.

\section{Curriculum Coverage According to Pacesetters}

Table 7 shows that of the teachers' curricula coverage according to pacesetters. Its results show that $73.3 \%$ of the respondents always cover the curriculum according to pacesetters. This is a good percentage when compared with the $0.7 \%$ of those who never do so. The results indicate that teachers are able to cover the content prescribed for the academic year. The completion of work according to pacesetters gives learners an added advantage when it comes to their examinations. The principals said that if teachers cover the curricula accordingly, it becomes easy for learners to respond to questions in different sections of the subject.

TABLE 7

THE EXTENT TO WHICH TEACHERS COVER THE CURRICULUM AS REQUIRED BY THE PACESETTERS

\begin{tabular}{lll}
\hline Scale & Frequency & Percentage \\
\hline Never & 1 & 0.7 \\
Seldom & 2 & 1.5 \\
Sometimes & 10 & 7.4 \\
Often & 23 & 17.1 \\
Always & 99 & 73.3 \\
\hline Total & $\mathbf{1 3 5}$ & $\mathbf{1 0 0}$ \\
\hline
\end{tabular}

This is how the principals responded, starting with principal E,

"At the beginning of the year, the SMT members, especially the HODs, sit down with their subject teachers where they go through how pacesetters should be used in line with the curricula. We always monitor to find out whether they are able to cover the curricula as per the pacesetters. So far, they are able to do so".

Principal $\mathrm{H}$ pointed out that,

"In our school, we monitor curricula delivery according to individual subjects. We also check progress in terms of curricula coverage as per the pacesetters. I have noted that teachers teach as per pacesetters and hence covered the curricula accordingly. Some are ahead of the pacesetters and they do revision with learners. This assist our learners a lot, especially our Grade 12 classes that have the highest number of the QP learners".

The result present in table 7 and the views of the principals on teachers covering the curriculum content are consistent, and in alignment with Fleisch (2016) argument that teachers should teach and cover what is prescribed in the curriculum before learners write the end of year examinations. Curriculum coverage is an integrated tracking tool which focuses on planned activities, activities that have been completed, list of topics not yet done and the planned interventions (Fleisch, 2016). Fleisch (2016) goes on to say that teachers should teach and cover all aspects of the curricula. These results suggest that the majority of teachers are able to cover curricula as per pacesetters. Thus, the learners' performance is likely to improve.

\section{Workshops on Content Delivery}

Table 8 shows the extent to which teachers are workshopped on delivering content to the QP learners.

The results in Table 8 show that $28.9 \%$ of the respondents are always workshopped on how to deliver content to the QP learners, and $24.4 \%$ indicated to the contrary. This means that the majority of the teachers might find it difficult to deliver content to the QP learners as they lack knowledge and understanding on how to do so.

TABLE 8

TEACHERS AND WORKSHOPS ON THE CONTENT DELIVER TO QP LEARNERS

\begin{tabular}{lll}
\hline Scale & Frequency & Percentage \\
\hline Never & 33 & 24.4 \\
Seldom & 11 & 8.1 \\
Sometimes & 19 & 14.2 \\
Often & 33 & 24.4 \\
Always & 39 & 28.9 \\
\hline Total & $\mathbf{1 3 5}$ & $\mathbf{1 0 0}$ \\
\hline
\end{tabular}

The interviewees acknowledge that workshops attended by teachers do not specify any category of learners, but are inclusive of all learners. The interviewees complained that the Department of Education wants schools to implement the progression policy, yet it does not play its part on how to teach learners once progressed. The following are remarks made by four principals. Principal A said of the whole issue,

"No, there are no workshops organised and conducted by the Department of Education to workshop teachers on how to deliver content to the QP learners. Teachers have to devise some mechanisms on how to deliver content that covers all learners as classes are mixed with promoted and progressed learners".

Principal B was a bit hash in his complaints, arguing that,

"The Department of Education just imposes policies on us. There is no direction on how to teach these QP learners to cover content gaps from previous grades as they do not conduct workshops on how to deliver such content to these 
learners. They do not workshop us on how to handle these QP learners. It is so frustrating".

Principal E also complained about teachers not being workshopped on how to teach the QP learners by the Department of Education, but the progression policy has to be implemented. He continued thus,

"We do in-house workshops at school on our own. We do train each other on how to identify where the learners lack in individual subjects, and where teachers should put more effort. What we workshop emanate from item analysis".

Principal $\mathbf{J}$ also felt that something must be done in the absence of workshops that should be conducted by the DBE. He concluded thus,

"We are not workshopped by our Department of Education, but at school we try to do something, specifically for the QP learners. We guide teachers through different approaches on how to teach these learners as they are slow performers who need assistance".

The above extracts imply that even though the Department of Education indicated that teachers should have knowledge that enable them to teach the grades they have been given, they do not provide workshops to capacitate them on content delivery concerning the QP learners. Responses from the respondents epitomise the need for the DBE to organise and conduct workshops for teachers on how to deliver content to QP learners. The fact that teachers are not workshopped on how to deliver content to such learners shows that it may be difficult to assist them improve their academic performance.

\section{CONCLUSIONS}

The study investigated the support strategies made available for progressed learners using 10 selected secondary schools in Vhembe district in Limpopo Province of South Africa. The samples of the study comprised teachers and SMT members from across the selected secondary schools. The data for this study was collected using questionnaire and interviews from teachers and SMT members respectively. Following the analysed data, the study findings showed that while the selected secondary schools are aware of the policy on progressing learners, and try to comply to it, the necessary supports are lacking.

Sequel to the findings of the study, the following recommendations are made: Support mechanisms / strategies should be put in place to assist progressed learners in catching up with their counterparts and getting better academically. This can be done by schools, and the Department of Basic Education (DBE), possibly with the assistance of other relevant education stakeholders. In this regard, the policy of progressing learners becomes worthwhile. This can be done through regular periodic workshops for both the learners and teachers teaching them. While the teachers would be trained on how to assist such progressed learners, the learners would be motivated and taught various learning skills;

The needed enhancing teaching and learning facilities are to be made available in schools. In this regard, the trainings provided to teachers can be relevant. This can be done by benchmarking best practices across the globe.

\section{ACKNOWLEDGMENT}

We would like to thank the research office as well as the Faculty of Education of the University of Zululand, South Africa for the continuous support towards this project.

\section{REFERENCES}

Creswell, J.W. (2014) Research Design: Qualitative, Quantitative and Mixed Methods Approaches (4th edn), Thousand Oaks, CA, Sage.

Department of Basic Education (DBE) (2017). Basic Education on policy on progression and policy on multiple examination opportunity. Available at: https://www.polity.org.za/article/dbe-basiceducation-on-policy-on-progression-and-policy-onmultiple-examination-opportunity-2017-10-31. Accessed 20 May 2021

Fleisch, B. (2016). System-wide improvement at the instructional core: Changing reading teaching in South Africa. Journal of Educational Change, 17(4): 437-451.

Hattie, J. (2009). Visible Learning: A Synthesis of Over 800 Meta-Analysis Relating to Achievement. Routledge: London.

Kumar, R. (2019). Research Methodology: A step by step guide for beginners. Sage. Australia.

Leepo, S.R. (2015). Strategies to deal with academic underperformance in Grade 12 in Free State. Central University of Technology. Free State.

Mansfield, M., \& Horwitz, D. (2020). The high drop-out rate, not the matric pass rate, should be a national obsession. Available at: https://www.dailymaverick.co.za/article/2020-0123-the-high-drop-out-rate-not-the-matric-pass-rateshould-be-a-national-obsession/. Accessed 20 May 2021

Moodley, P., \& Singh, R.J. (2015). Addressing student dropout rates at South African universities. Alternation. Special Edition 17: 91-115.

Opfer, D. (2016). "Conditions and Practices Associated with Teacher Professional Development and its Impact on Instruction in TALIS 2013", OECD Education Working Papers, No. 138, OECD Publishing, Paris.

Park, K., Ji, H. \& Lim, H. (2015). Development of a learner Profiling System Using Multidimensional Characteristics Analysis. Korea University, Seoul, Republic of South Korea.

Pitre, C. (2010). School attendance: Understanding the process and complexities from diverse perspective. Available at: http//www.rainbowschools.ca. Accessed 24 July 2014.

Pretorius, L. (2019). Dropout rates: Is South Africa among the worst in the world? Available at: https://www.news24.com/citypress/news/dropout- 
rates-is-south-africa-among-the-worst-in-the-world20190304. Accessed 20 May 2021.

Tomlinson, C.A. (2001). How to differentiate instruction in mixed classrooms. Association for Supervision and Curriculum Development (ASCD): Alexandria, Virginia USA.

Uleanya, C. (2020): Rural undergraduate university students' learning challenges in Africa: case study of Nigeria and South Africa, African Identities, DOI:10.1080/14725843.2020.1813083

Weybright, E. H., Caldwell, L. L., Xie, H. J., Wegner, L., \& Smith, E. A. (2017). Predicting secondary school dropout among South African adolescents: A survival analysis approach. South African journal of education, 1353. https://doi.org/10.15700/saje.v37n2a1353

Writer, S. (2020). This is the school dropout rate in South Africa. Available at: https://businesstech.co.za/news/government/438509 /this-is-the-school-drop-out-rate-in-south-africa/ Accessed 20 May 2021. 